\title{
A iluminação do espaço público da Cidade do Rio de Janeiro (1990-2015)
}

Marcos Paulo Ferreira de Góis ${ }^{1}$

\begin{abstract}
RESUMO
A noite urbana tem adquirido cada vez mais um relevante papel nas políticas públicas municipais, ora como elemento para se pensar a infraestrutura urbana, ora como momento para a concretização e exposição de obras estéticas e atividades de lazer e entretenimento. Neste artigo será observada, principalmente, a atuação do Estado na transformação da paisagem noturna carioca, em seus diferentes momentos desde o início da década de 1990 até os dias atuais, tendo como centro de observação a iluminação dos espaços públicos do município do Rio de Janeiro. Assim, notase uma mudança da política urbana, inicialmente centrada no problema da iluminação como infraestrutura, e posteriormente dedicada ao estabelecimento do papel da iluminação artificial como elemento de valorização estética da paisagem. Verifica-se que a iluminação artificial é um elemento central para as pesquisas sobre a paisagem e as vivências noturnas, implicando em relações com problemas mais amplos de ordem social, como a segurança, a orientação, a visibilidade, os valores e os comportamentos urbanos. Esta amplitude parece confirmar o seu papel como elemento interdisciplinar para o pensamento sobre o urbano.
\end{abstract}

PALAVRA-CHAVE: Paisagem noturna; Iluminação pública; Planos urbanos; Rio de Janeiro

\section{ABSTRACT}

Public policies are increasingly influenced by a discussion about urban night, which sometimes addresses the role of lighting as part of urban structure and other times presents night as a time for leisure and entertainment activities. Changes on nightscapes can be related to two kinds of rhythms: a more extended duration and progressive actions that can be viewed as modifications on morphology; and a more subtle combination of actions that occurs on a daily cycle. The dialogue between these two rhythms creates a rich frame of space-time relations that can be a field of work for those interested in the urban landscape. In this paper we aim to observe how Rio's local government acts on landscape transformations, especially in the way night dialogues in their plans since the beginning of the 1990's. As a result we can see that small changes in urban policies, initially centered on the problem of light as urban structure, and thereafter focused on the idea of lighting as a tool for landscape exhibition and tourism. Thus, it is relevant to point that artificial light plays a central role for those working on nightscapes and urban life, combining different kinds of problems as security, spatial orientation, visibility, social values and behavior patterns. This amplitude seems to confirm how significant light can be for those who are concerned about urban space and social time.

KEY-WORDS: Nightscape; Public lighting; Urban planning; Rio de Janeiro.

\section{A noite, a luminosidade e a visibilidade das práticas sociais}

É comum ouvirmos que durante a noite todos os gatos são pardos. Essa expressão popular tem como referência o fato de que à noite não vemos as coisas de forma tão clara como durante o dia, que temos dificuldades em reconhecer as nuances das cores e que temos limitados recursos de distinção visual em relação ao que se apresenta ao nosso olhar. A expressão sugere, além disso, que tal barreira visual permite, ao mesmo tempo, que as ações praticadas durante a noite podem passar despercebidas ou mesmo ignoradas pela

1 Doutor em Geografia - Universidade Federal Fluminense, Angra dos Reis - Rio de Janeiro 
baixa visibilidade. Esta relativa dificuldade em ver as coisas é o que nos permite dizer que existe uma paisagem noturna composta pela variedade de luzes e sombras que ajudam a exibir ou a esconder lugares, objetos e pessoas. Mais do que isso, é importante afirmar que se durante o dia há maior imposição da iluminação natural; durante a noite o que se percebe é uma clara intencionalidade na disposição da luminosidade. Por isso, afirmamos que a paisagem noturna é um resultado intencional de escolhas arbitrárias tomadas por diferentes agentes sociais de uma cidade em relação à iluminação artificial do espaço.

A especificidade da iluminação artificial também é realçada em virtude de sua excepcionalidade para o entendimento da seletividade de sua disposição no espaço. Este sofisticado aparato é um elemento ativo na configuração da forma urbana e do uso social, podendo até mesmo ser um agente que impõe limites e dispõe potencialidades para a apropriação social (Bennett, 2010). Além de ser um elemento da paisagem noturna, as luzes artificiais podem também revelar espacialidades, princípios morais, identidades, formas de sociabilidade entre outros (Bille e Sorensen, 2007). A noite assim observada exige a compreensão da diferenciada distribuição de luzes (e de sombras) e de seu valor para a constituição da vida urbana.

Além do caráter intencional da ação de iluminar, cabe também afirmar o fato de que esse processo tem um caráter cíclico, ritmado e efêmero, sendo, portanto, um espetáculo cotidiano de afirmação dos valores sociais. A paisagem noturna de uma cidade é constituída, simultaneamente, por sua materialidade e, consequentemente, pela visibilidade dessa materialidade e pelas ações, práticas ou comportamentos dos indivíduos e grupos que a vivenciam e a produzem cotidianamente. Como materialidade, a paisagem noturna possui visibilidade limitada, seletiva e temporária. Esta condição se dá em razão de múltiplas variáveis, como o ritmo, a ocupação, a disponibilidade de luminosidade natural, as decisões sobre a localização da iluminação artificial, entre outras. Neste sentido, aquilo que se vê é diretamente influenciado por decisões de âmbito social, sobre o que se quer exibir. A forma urbana sob este aspecto ganha uma capa de visibilidade diferenciada durante o período noturno, o que pode gerar uma distinta impressão sobre a paisagem, bem como novas ações que têm ligações exclusivas com este período do dia.

No passado remoto dos povoados isolados, das vilas campesinas ou dos primeiros aglomerados urbanos o que se via na paisagem noturna era, talvez, apenas alguns postes e braços de luz bruxuleantes iluminando fachadas de prédios públicos. As luzes, quando presentes, pareciam realçar o ar sombrio das cidades (Dunlop, 2008). A transformação desse cenário é relativamente recente e possui forte relação com o desenvolvimento de tecnologias de iluminação moderna, especialmente com a introdução da energia elétrica e das lâmpadas incandescentes (Mendonça, 2004).

Porém, não se deve esquecer que o ato de iluminar áreas públicas se remete ao interesse social no uso de tais espaços, a partir do surgimento de novas atividades durante o período noturno. Somente assim poderemos pensar em um sentido social da noite, a qual incorpora em suas horas cada vez mais lazer e trabalho humano (Melbin, 1987). O avanço desse processo não ocorreu somente ao longo do tempo, mas também ao longo do espaço, absorvendo áreas que até então estavam submetidas aos interesses das atividades diurnas. O mundo do trabalho e do lazer noturno foi, paulatinamente, se apropriando de novas áreas, fragmentando as cidades também durante a noite em polos com diferentes funções sociais, o que resulta, sem dúvida, de ações planejadas por parte do poder público e do empresariado urbano (Gwiazdzinski, 2005).

É um tanto quanto incomum que se observe paisagens durante o período noturno, mas espera-se que a partir das ações e dos planos urbanos se consiga ver intencionalidades, valores, significados associados à paisagem noturna. Como apontou Meinig (1979) a paisagem deriva das ideias daqueles que a observam e que agem sobre ela. Ela pode ser 
vista como um potencial recurso para mobilizar interesses sociais. A paisagem à noite, coberta pela luminosidade artificial pode denotar sentidos e "fazer ver" outros elementos que estariam "escondidos" sob a capa da luminosidade zenital oriunda do Sol. As ideias daqueles que têm como seus principais atributos o planejamento urbano perfazem planos e projetos que transformam e dão sentido à paisagem noturna.

Neste artigo será apontado o aspecto processual de configuração da noite, especialmente como o Estado atua por meio de planos, projetos e ações. De uma forma menos direta são apresentadas algumas consequências para o cotidiano da cidade, sem que, no entanto, se avance em direção a uma explicação mais detalhada de seu arranjo espacial e social. Antes de se apresentar os planos, os projetos e as ações para a paisagem e a vida noturna carioca, ainda se pode afirmar que as suas consequências foram percebidas pela ativação de alguns espaços públicos a partir da observação empírica de atividades sociais durante a noite entre os anos de 2009 e 2015. Além disso, o entendimento das consequências foi reforçado pela análise de material hemerográfico do período, bem como de trabalhos de outros pesquisadores, incluindo pesquisas de opinião com a população residente do município. No entanto, o uso desse material teve neste artigo uma importância menor. Um exame mais abrangente desses dados pode ser encontrado em Góis (2017).

Por fim, se afirma o caráter espacial das ações de iluminar a cidade, não apenas como elemento da infraestrutura urbana, mas como aspecto simbólico, matriz técnica que exibe espaços para o viver e para o olhar. Notamos os lugares que estão sob a luz de um poste, as placas que sinalizam rotas, as fachadas iluminadas de prédios, as propagandas luminosas, os monumentos urbanos. Escolher o que se quer exibir da paisagem durante a noite exige a consideração sobre a luminosidade. Esta seletividade espacial fornece pistas para aqueles que procuram entender o sentido da localização dos valores e dos comportamentos sociais (Gomes, 2012). Veremos a partir de agora como se organizam essas intenções e como a busca pelos seus sentidos nos ajuda a compreender a paisagem noturna carioca.

\section{Luzes para o zoneamento noturno e a expansão urbana}

A vida nas cidades durante o período noturno é uma preocupação recorrente ao longo da história, principalmente em razão dos conflitos sociais decorrentes da pouca visibilidade (Melbin, 1987). Nesse sentido, o poder público por meio de seu aparato policial tem tentado reduzir os problemas ao introduzir nas cidades mecanismos de iluminação que garantiriam a redução dos problemas relacionados ao noturno (Schivelbusch, 1987). É significativo notar que tais medidas raramente foram tomadas em conjunto com o próprio processo de expansão urbana e permaneceram até bem pouco tempo limitadas ao núcleo urbano consolidado. A ampliação do acesso à rede de iluminação pública, especialmente no caso brasileiro, ainda é uma realidade bastante recente, resultado de ações de padronização e de gestão eficiente da energia elétrica (Mendonça, 2004).

O problema da iluminação pública foi abordado dentro de um contexto mais amplo, categorizado como sendo parte dos mecanismos de construção de infraestrutura urbana (Mascaró, 2006). Por um lado, esse modelo propiciou uma expansão da iluminação pública em toda a malha urbana; por outro, o planejamento de tais intervenções se tornou parte de um sistema de intervenções estratégico para a melhoria de vida na cidade. De um lado se acertariam os pontos com as demandas de apropriação social, resolvendo conflitos e promovendo novas formas de sociabilidade; por outro, se investiria em propostas de zoneamento urbano que incorporassem as vocações locais, adaptando, assim, os espaços físicos e as práticas sociais. 
O planejamento da noite carioca seguiu alguns desses princípios e adotou o modelo do urbanismo luminoso como um guia no caminho para a renovação ou revitalização dos seus espaços públicos. Este modelo teve importantes repercussões em cidades europeias e americanas, especialmente com a idealização de planos diretores de iluminação artificial e zoneamentos noturnos (Narboni, 2004). Na cidade do Rio de Janeiro, o urbanismo luminoso foi adotado pela prefeitura nas gestões de Cesar Maia (1993-1996) e Luiz Paulo Conde (1997-2000) como um princípio norteador das ações da Rio Luz, empresa responsável pela manutenção do sistema de iluminação pública carioca. Durante este período, o arquiteto José Canosa Miguez assumiu a diretoria de projetos da Rio Luz e o urbanismo luminoso se tornou um elemento a ser traduzido para a realidade local (Miguez, 2001). Os manuais, as diretrizes e as pesquisas realizadas neste período ainda são as bases para os projetos da prefeitura, incorporando parte do modelo francês de gestão da noite urbana na gestão de Eduardo Paes (2009-2016), por exemplo.

Ainda que não possamos aprisionar a ideia de gestão da cidade às atividades do governo local, suas medidas possuem, em geral, relação com suas atribuições de planejamento e de execução de uma política urbana (Brasil, 2001). A iluminação pública é um de seus atributos e corresponde à parte daquilo que se convencionou chamar de infraestrutura urbana, sendo objeto integrante dos novos planos diretores, projetos urbanos e planos setoriais desenvolvidos no contexto da descentralização administrativa dos anos 1980 . Neste contexto, a iluminação pública passa também a ser um dos principais instrumentos para se pensar a vida noturna nos espaços públicos das cidades, tendo, com isso, relação com outros setores prioritários de governo como, a segurança, o turismo, o patrimônio, o desenvolvimento econômico, entre outros.

A adoção de um modelo não significa necessariamente o abandono de práticas antigas. 0 poder público local permaneceu atuando conforme alguns dos princípios já tradicionais, pensando a iluminação pública também como elemento da infraestrutura urbana, ao lado do saneamento, do abastecimento d'água e do asfaltamento de ruas. A ideia era que estes componentes promovessem o progresso ou, em geral, a melhoria da vida dos habitantes. Desta maneira, a luz artificial apareceu nos instrumentos de política urbana, articulando, ao mesmo tempo, noite e dia na concepção de uma cidade que precisava ajustar a sua dívida socioespacial, controlando a expansão e melhorando a habitabilidade.

A aprovação da Constituição Federal Brasileira em 1988 foi um marco na história da democracia no país e afetou diretamente o papel do poder público local na definição dos parâmetros urbanos e fundiários, o que possui laços importantes com o que foi assinalado acima. Os artigos 182 e 183 da Constituição Federal dedicados à política urbana são especialmente relevantes, pois, não só deram ao poder público municipal a responsabilidade pela execução da política de desenvolvimento urbano, como também obrigaram as cidades com mais de vinte mil habitantes a discutir, aprovar e implementar um Plano Diretor. Esta atribuição teve como consequência a criação de uma imagem da cidade, ou seja, um quadro-diagnóstico que revelava a amplitude das dificuldades que teriam que ser enfrentadas pela municipalidade no horizonte de dez anos.

O primeiro Plano Diretor do município (1992) foi um experimento com significativas limitações, o que pode ter sido o resultado de uma visão ainda muito pouco clara sobre o seu papel e potencial. O Plano acabou tendo o mesmo problema de outros planos diretores criados no período, estando ainda atrelado a um modelo tradicional de caráter francamente modernista de zoneamento urbano (Feldman, 1997). O perfil do Plano acabou sendo incorporado pelo governo dos prefeitos e pode ser observado em outros instrumentos de gestão e mesmo nas diretrizes de execução de obras, relevando que a sua importância se consagrou na prática e delineou elementos da paisagem carioca. 
Há ainda outros elementos de avaliação do Plano Diretor que poderiam ser ressaltados, mas no que se refere à iluminação do espaço urbano há muito pouco a ser dito, pois não há nenhuma menção sobre o espaço urbano durante a noite, incluído somente como parte do planejamento global da cidade. A iluminação, por exemplo, é mencionada em cinco momentos dentro do Plano Diretor:

a. Como parte de equipamentos urbanos a serem instalados para a recuperação da área da Cidade Nova (Art. 62-II);

b. Como estrutura de valorização turística da área da Baía de Sepetiba (Art.71- $\mathbb{1} 1^{\circ}$ );

c. Como parte do índice urbanístico para edificações (Art.108- $\mathbb{3} 3^{\circ}$ );

d. Como mecanismo de complementação à urbanização (Art. 152- $\mathbb{3} 3^{\circ}$ );

e. E, por fim, para o "estabelecimento de critérios para implantação e melhoria dos serviços de iluminação pública, considerando-se a hierarquia das vias, a população beneficiada e a precariedade dos equipamentos instalados" (Art. 189-X).

Em nenhum dos casos, entretanto, há qualquer detalhamento ou mesmo caracterização do papel da iluminação para as áreas consideradas, o que é condizente com o modelo mais geral de apresentação das diretrizes no Plano. No entanto, a sua vinculação ao processo de urbanização é destacada, pois, embora complementar, a iluminação pública é tida como mecanismo efetivo para a expansão urbana e melhoria do bem-estar. Ao mesmo tempo, as áreas consolidadas precisavam ser "revitalizadas" de seu estado de relativo abandono, o que incorporava também uma maior visibilidade do espaço. Estes dois pontos demonstram a urgência que parecia ter para o governo local um zoneamento urbano noturno condizente com as potencialidades das diferentes áreas.

Uma das novidades oriundas do Plano Diretor era a possibilidade de criação de Planos Setoriais, os quais desdobrariam as propostas mais gerais em linhas de atuação específicas, como trânsito, segurança, jardins, saneamento etc. Entre eles, a iluminação pública recebeu diretrizes específicas com a criação de Plano Diretor de Iluminação Pública. Este Plano, criado em 1993, buscou seguir alguns dos princípios do Plano Diretor Municipal, especialmente no que se refere a um planejamento regional, especificando medidas a serem tomadas em toda a cidade, buscando reduzir as disparidades na oferta dos serviços. O Plano Diretor de Iluminação Pública se tornou o instrumento responsável pela organização espacial da cidade para o período noturno através do estabelecimento de metas centrais, como, por exemplo, a iluminação de todos os logradouros da cidade, a redução do consumo de energia e a adequação da iluminação às funções urbanas dos logradouros.

As metas visavam alcançar objetivos mais concretos, como a promoção de conforto e segurança para as atividades noturnas, a distribuição espacial mais justa dos investimentos e a expansão da área de cobertura do sistema em toda a cidade. Para se alcançar tais objetivos, foram criadas estratégias de atuação como, por exemplo, a padronização dos serviços, dos equipamentos, dos materiais empregados e o treinamento de pessoal dentro de uma modelo de gestão "mais moderno" que deveria ser implantado com a consolidação da Rio Luz como autarquia responsável pela iluminação pública do município.

O discurso sobre a gestão da tecnologia se baseou em estudos de ordem estatística e sua aplicação geográfica, criando um diagnóstico da espacialização da iluminação pública em todo o município. O levantamento de tal espacialização resultou em uma estratégia de atuação na malha urbana, com evidentes interesses sobre as áreas de expansão urbana, nas Zonas Oeste e Norte do município. O resultado deste levantamento estabeleceu os parâmetros de atuação da empresa para os dez anos seguintes (1993-2002), quando um novo Plano Diretor deveria ter sido criado. 
Dentre os resultados, se destaca a desigual distribuição espacial do serviço de iluminação pública no município. As áreas de expansão urbana acelerada - áreas de planejamento $4 \mathrm{e}$ 5 , Zona Oeste - sofriam com a carência de equipamentos de iluminação nas suas principais localidades. Bairros como Campo Grande, Santa Cruz, Bangu e Guaratiba tinham até 1993 menos de $50 \%$ de seus logradouros cobertos por iluminação pública. A Zona Norte também receberia atenção especial no Plano, muito em razão da decadência e da falta de manutenção da iluminação pública nos subúrbios da Central do Brasil. Estas duas áreas deveriam estar sob o foco dos investimentos entre 1993 e 2002, concentrando cerca de $70 \%$ do capital investido pela Rio Luz. Na figura 1 notam-se as áreas hachuradas que indicam as zonas que deveriam concentrar as ações de melhoria da iluminação pública no município.

Apesar do investimento, o plano de metas teve que lidar com a rápida expansão daquelas áreas do município. É interessante notar que nas áreas planejadas houve um incremento de cerca de 800 mil habitantes em pouco menos de vinte anos, momento em que um novo Plano Diretor foi redigido. Em resumo, as ações de iluminar os logradouros públicos não tiveram como avançar na mesma velocidade que a cidade se expandia para os limites do município. A ampliação da demanda certamente teve impacto na qualidade do serviço e deve ter gerado, ao mesmo tempo, uma expansão do problema da iluminação para toda a cidade. Observada a expansão urbana - e os processos espaciais resultantes dessa expansão -, atuaria o governo local como um agente importante, não somente na iluminação da paisagem do Rio de Janeiro, mas como promotor da vida noturna, gerando novos lugares de sociabilidade e ordenando as práticas no espaço.

FIGURA 1: Metas de investimento da Rioluz para os anos 1990

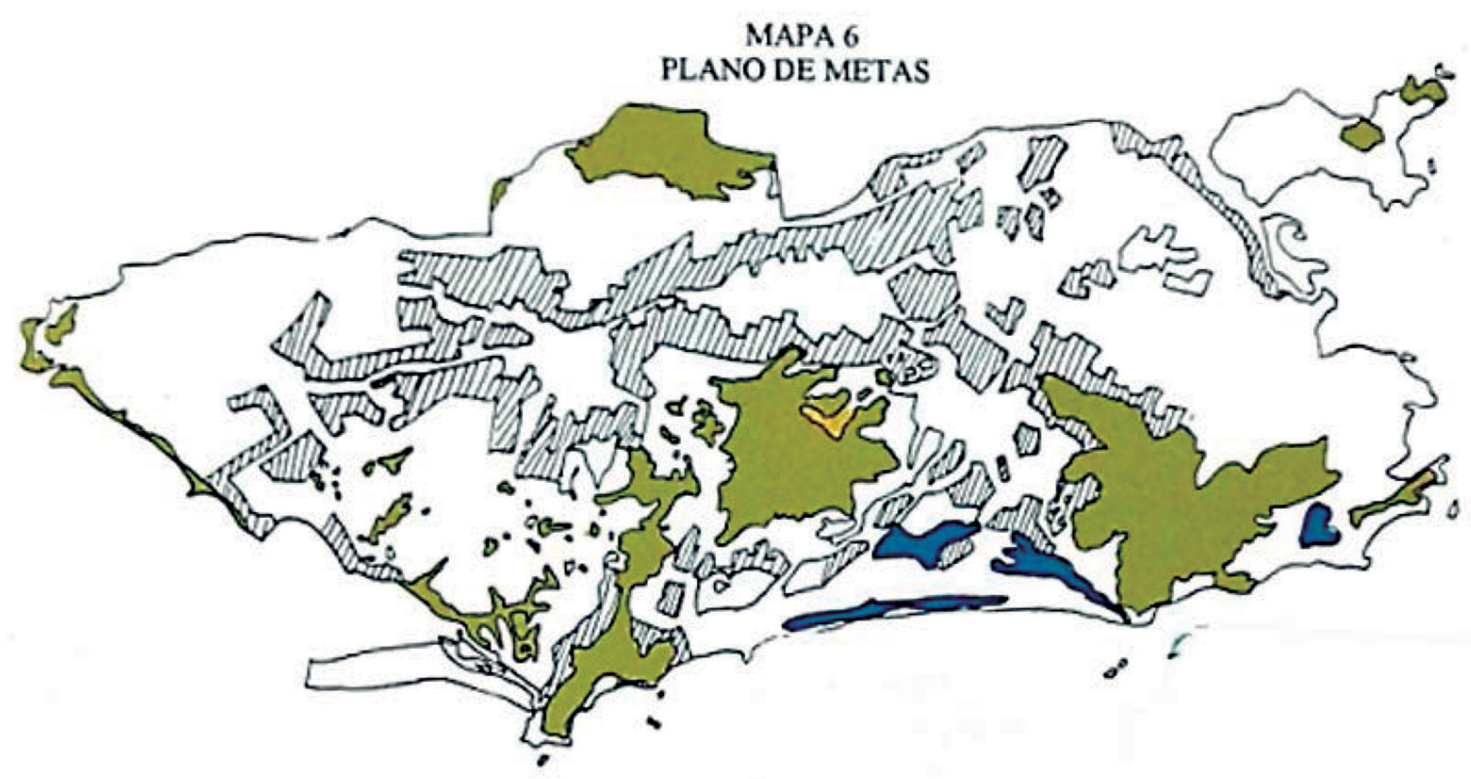

Na figura as áreas hachuradas indicam as metas de investimento prioritário da Rioluz. Fonte: Rio Luz:

Plano Diretor de Iluminação Pública, 1993, p. 33.

O Plano Diretor de Iluminação Pública foi um passo adiante na tentativa de incluir a noite nas políticas urbanas do município, mas a sua abrangência teria que ser revista, de forma constante, a partir da introdução de novos projetos e de linhas estratégicas que aderiam às ações dos prefeitos. Cada gestão teve uma forma de atuar, mas, de maneira bastante geral, pode-se afirmar que a iniciativa se deu por meio dos projetos urbanos e das colaborações entre níveis de governo. Sem a participação dos agentes de governo locais e a associação entre iluminação artificial e projetos de espaço público, acabaria a municipalidade restrita ao uso da iluminação pública como elemento de infraestrutura urbana. 


\section{Luzes para o embelezamento e a gestão eficiente}

O planejamento municipal encontrou significativas barreiras para se tornar efetivo e encaminhar transformações na paisagem noturna do Rio de Janeiro. De um lado a própria expansão da cidade aumentou a demanda por novos equipamentos de iluminação, pela reforma de logradouros e pela melhoria dos espaços públicos. Apesar disso, as ações do governo local acabaram criando alterações na morfologia urbana, na sua visibilidade noturna e até mesmo nas práticas sociais. $O$ Plano Diretor e os planos setoriais permitiram que uma visão mais geral do município fosse estabelecida, fragmentando a cidade em áreas prioritárias de investimento. Em colaboração aos planos surgiram também alternativas de execução em dois caminhos estratégicos: a primeira esteve relacionada a novas formas de gestão da energia elétrica nas cidades e foi promovida em parceria com o Governo Federal; a segunda dizia respeito à adoção de novos modelos de urbanismo noturno, encaminhados a partir de projetos urbanos.

Mudanças na paisagem noturna da cidade foram criadas dentro de um quadro mais amplo de transformações na visão sobre o papel da luz na vida social. A iluminação artificial antes vista como símbolo da modernidade e da genialidade humana, passou a ser interpretada, a partir da década de 1970 em diante, como um elemento que poluía o ambiente e interferia nas relações do homem com o meio. A poluição luminosa passou a estar associada a outras formas de contaminação do meio pelo uso desregrado dos recursos naturais e da tecnologia (Bogard, 2008). Os especialistas nas técnicas de iluminar as cidades passaram a adotar esta preocupação, a qual, aos poucos, passou a ser assimilada pelos agentes públicos (Santen, 2006). A eficiência luminosa deveria, ao mesmo tempo, evitar o desperdício de energia e limitar a influência da luz artificial nos ciclos da natureza, se restringindo às suas funções sociais em termos de área (Kirschbaum, 2006).

O governo brasileiro incorporou a discussão sobre a poluição luminosa ainda na década de 1980 através do Programa Nacional de Conservação de Energia Elétrica (PROCEL), o qual visava criar melhorias na gestão da energia elétrica nacional, com a proteção dos recursos ambientais. Assim, novas formas de produção, consumo e de aparelhos eficientes deveriam garantir a redução dos gastos com a energia e o melhor aproveitamento dos recursos. Trata-se, na verdade, de um grande programa que inclui a gestão de prédios públicos, maquinários e eletrodomésticos, incluindo equipamentos industriais entre outros procedimentos. O Procel-Reluz (Programa Nacional de Iluminação Pública e Sinalização Semafórica Eficientes) criado em 2000 aliou-se a esses outros programas em busca da melhoria da eficiência dos serviços públicos ligados ao uso da energia elétrica, bem como a valorização noturna dos espaços públicos urbanos (PROCEL, 2005).

Havia a expectativa de que o Programa gerasse mudanças significativas na paisagem e na vida noturna dos municípios. Os benefícios esperados incluíam melhorias relacionadas à segurança pública, especialmente nos aspectos relacionados à proteção da população urbana, à segurança do tráfego viário e à qualidade de vida. Outros desdobramentos incluíam a melhoria da imagem das cidades brasileiras, das condições de vivência dos espaços públicos e a ampliação das atividades noturnas de lazer, das práticas desportivas, do comércio e dos postos de trabalho. Em parte, as mudanças ocorreriam gradualmente com o ampliação e melhoria da iluminação pública em áreas residenciais, comerciais e de grande circulação. A ideia era que, afinal, a iluminação pudesse ser associada a um processo educativo de valorização de bens referenciais para o poder público e para a comunidade.

No caso do Rio de Janeiro, o Procel-Reluz foi um importante veículo para a redução dos custos e aceleração do cumprimento das metas estipuladas pela RioLuz em 1993. Com o investimento de cerca de $75 \%$ do valor total dos projetos, a Eletrobrás desonerou os custos para o governo local e promoveu o equilíbrio das contas da Rio Luz entre 2000 e 2008. Soma-se a isso o crescimento do espaço urbano da cidade para as Áreas de Planejamento 
4 e 5, multiplicando o número de logradouros públicos e, consequentemente, a demanda por pontos de luz. Aparentemente, o Procel-Reluz conseguiu atingir sua principal meta, melhorando a eficiência energética através da adoção de materiais modernos na iluminação pública. A reformulação dos pontos de luz permitiu uma queda do consumo de energia elétrica da ordem de $30 \%$, segundo dados obtidos no Instituto Pereira Passos para o período entre 1992 e 2010.

A municipalidade, ciente das novas demandas para um desenvolvimento sustentável e para uma redução significativa dos gastos públicos, aderiu ao projeto nacional por meio de projetos urbanos que dialogaram também com as diretrizes do Plano Diretor de 1992. Os projetos urbanos foram a abordagem encontrada pela municipalidade para lidar com os problemas da expansão urbana e da crise econômica na cidade. Durante a década de noventa os projetos urbanos receberam uma grande acolhida pelas municipalidades em detrimento dos grandes planos que orientaram a política precedente de reformas urbanas. A estratégia dos projetos, ainda que questionada pelo seu caráter pontual e complementário (Novick, 2004), pode ser também vista como um mecanismo eficiente de gestão dos gastos públicos (Lerner, 2014).

Desde os anos 1990 o uso dos espaços públicos durante a noite tem sido um tema que percorre os projetos da cidade. Boa parte das melhorias na iluminação pública foi conquistada a partir de projetos urbanos como o Rio Orla, que produziu reformas nas áreas costeiras do município; o Rio Cidade, que promoveu a reurbanização de centros comerciais de bairros; o Corredor Cultural que tem auxiliado na reconfiguração do cenário urbano da área central; e o Favela Bairro que buscou urbanizar e integrar áreas de favelas à cidade formal. Tais melhorias podem ser vistas nos espaços públicos de algumas áreas, o que inclui a criação de um padrão de intervenção e remodelação dos antigos materiais iluminantes em todo o município. Os projetos urbanos foram uma das soluções para afinar os objetivos da empresa Rio Luz com os interesses da Prefeitura Municipal.

Cada área da cidade recebeu um conjunto de intervenções dirigidas aos usos recorrentes e às potencialidades apresentadas nos diagnósticos dos projetos. Em boa parte dos casos o estímulo à vida noturna e à utilização dos espaços públicos foi reforçado pela criação de projetos que valorizaram os centros de bairro como locais comerciais e as áreas residenciais como lugares onde a iluminação possuía função de segurança e de orientação. A valorização estética e a visibilidade da paisagem noturna foram outros desdobramentos, mais comuns nas áreas com potencial turístico, ligado ao processo de patrimonialização, nos corredores da área central e nos marcos simbólicos da cidade, como os monumentos, igrejas, casarios e conjuntos naturais.

É importante observar que em todos os projetos citados anteriormente prevaleceram mudanças relacionadas ao espaço público, especialmente nas vias de circulação de veículos, nas calçadas e nas praças. Tais espaços foram remodelados para atender certas demandas de uso e de apropriação observados pelas equipes de arquitetura contratadas para desenvolver os projetos de urbanização. Tais diagnósticos podem ser encontrados na sede do Instituto Pereira Passos e foram parcialmente comentados em Góis (2015). É importante notar que o viés dessas intervenções seguiu as considerações arroladas acima sobre o urbanismo luminoso e as tentativas de dirimir os problemas associados ao custo de manutenção do sistema e da geração de poluição luminosa.

Parece ser crucial apontar, afinal, que tais mudanças ocorreram em um tempo relativamente breve, com pouco menos de vinte anos, quando um novo zoneamento urbano foi pensado e novas centralidades emergiram do processo de recuperação dos espaços públicos do município. As mudanças relocalizaram a vida noturna, alterando os ritmos urbanos de áreas como a Lapa, no centro da cidade, os centros comerciais do subúrbio e as antigas áreas boêmias da Zona Sul. Os investimentos na Zona Oeste também expandiram os limites 
da vida noturna, em um processo de articulação entre poder público e iniciativa privada que inaugurou um novo modo de viver a noite carioca em shopping centers, boates e centros de entretenimento. Nestes casos, houve uma significativa aceleração dos ritmos, implicando em novas demandas para o governo local a partir de então.

\section{Luzes para ver a paisagem}

O novo Plano Diretor da cidade do Rio de Janeiro foi publicado no ano de 2011 após um longo debate em torno de seu conteúdo. Parte do atraso se deveu a adequação do plano às novas diretrizes trazidas pelo Estatuto da Cidade, como a ideia de uma gestão democrática da cidade, a viabilização das operações urbanas consorciadas e a criação de estudo de impacto de vizinhança (EIV). Tais mudanças tiveram papel relevante na redação final do Plano, especialmente no que diz respeito à centralidade dada aos aspectos relacionados ao desenvolvimento sustentável e à universalização do acesso aos bens urbanos. Fundamentalmente, as preocupações com as qualidades paisagísticas da cidade foram realçadas e a preservação do patrimônio natural e cultural da cidade receberam destaque no Plano em detrimento ao zoneamento, característica do Plano anterior. A paisagem foi concebida como o bem mais valioso da cidade, com intersecção dos elementos naturais, sociais e culturais na formação de um ícone urbano mundial.

A paisagem noturna ganhou, assim, um papel destacado frente ao antigo Plano que propunha uma visão de cunho territorial. O caso é que a questão da estética e da visibilidade das belezas da paisagem carioca passou a ter um papel mais importante no novo Plano. A articulação da paisagem noturna com a política urbana foi desenvolvida a partir da ideia de patrimonialização, tanto ambiental, quanto histórica e cultural. O turismo foi também um eixo articulador entre as necessidades da iluminação como infraestrutura para a segurança e orientação e o seu papel como elemento que destacaria os marcos espaciais da cidade. Nota-se que em relação à iluminação pública o novo Plano Diretor apresentou um desenvolvimento importante sobre o tema. O termo iluminação aparece relacionado a nove artigos do plano, sendo que um deles, o artigo 229, trata exclusivamente das ações relacionadas à iluminação pública. Neste caso, parece que a noite urbana começa a receber um tratamento diferenciado em relação ao interesse mais geral apresentado pelo Plano sobre a cidade:

Art. 229. São ações estruturantes relativas à iluminação pública:

I. ampliar a cobertura de atendimento, iluminando os pontos escuros da Cidade e eliminando a existência de ruas sem iluminação pública;

II. implementar planos de manutenção corretiva e preventiva;

III. elaborar o cadastro da rede de iluminação pública do Município;

IV. auditar e monitorar periodicamente as concessionárias de distribuição de energia que atuam na Cidade;

V. criar um programa para aprimorar a iluminação em pontos turísticos, monumentos, obras e edificações culturais e históricas;

Vl. estudar em conjunto com o órgão central do sistema de gestão ambiental, tipos de iluminação mais apropriados para Unidades de Conservação da Natureza, que utilizem espectros não impactantes para fauna.

Todos os quatro primeiros pontos do artigo não são, no entanto, novidades. O Plano Diretor de Iluminação Pública de 1993 já apresentava as mesmas preocupações. Contudo, os dois últimos pontos do artigo são novas visões sobre dois elementos centrais do novo Plano Diretor: a gestão do patrimônio e a gestão ambiental. A iluminação é incorporada 
como elemento de valorização do conjunto paisagístico carioca, sendo um elemento de ambientação para a prática do turismo urbano. Ao mesmo tempo, os problemas da poluição luminosa são contemplados pela primeira vez, realçando um caráter muito recente das discussões em torno da iluminação artificial urbana. Assim, a qualidade, durabilidade, eficiência e impactos da iluminação passam a fazer parte do debate sobre onde e como os equipamentos serão instalados na cidade. Além disso, permanece o papel de infraestrutura urbana para a iluminação pública, sendo um elemento no processo de expansão urbana relacionado, agora, à visibilidade da paisagem.

Dentro do mesmo contexto, uma comparação entre os dois planos estratégicos do governo municipal do prefeito Eduardo Paes mostrou uma mudança na forma e na intensidade com a qual se lida com o problema da iluminação. Nos dois casos o termo noite não aparece, mas o termo iluminação cresce substancialmente. As imagens noturnas também aparecem mais no novo plano do que no anterior, destacando a paisagem noturna como elemento que compõe o álbum de apresentação da cidade. Os principais projetos de infraestrutura do novo plano estratégico possuem em alguma parte uma preocupação com a iluminação pública. No plano estratégico há uma parte exclusivamente dedicada à modernização da rede de iluminação pública, incluindo a proposta de criação de um plano diretor de iluminação pública para o ano de 2013 - ainda não produzido - e o investimento de 1.373 milhões de reais no setor até 2016.

Parece que com isso, a gestão da prefeitura nos anos 2010 considera a iluminação um elemento estruturante de seus projetos, concedendo um lugar especial para sua análise. Caberá futuramente investigar as ações que se submeteram a esses planos e averiguar o seu papel na paisagem noturna carioca, apreendendo as práticas e as novas formas que surgiram de um novo modo de se pensar esta paisagem. Há ainda que se entender como estas transformações tem alterado o ritmo veloz das mudanças diárias, algo que extrapola o escopo deste artigo.

Torna-se importante, no entanto, sinalizar que as mudanças no pensamento estatal em relação ao noturno apresentam um diálogo entre o passado e o futuro, entre a busca da ordem urbana em meio aos processos de expansão do espaço urbano. Eficiência e estética são palavras importantes para o planejamento da noite e a iluminação pública é talvez um dos elementos centrais para a atuação do município. Esta não é, entretanto, a única forma de atuação do Estado, que age sobre a noite em outras frentes, regulando comportamentos, inibindo formas de ocupação e direcionando a economia noturna. Cada um desses pontos se abrem em novas frentes de pesquisas, as quais, infelizmente, não cabem neste espaço e só podem ser objeto de outras reflexões.

\section{Reflexões à guisa de conclusões}

A paisagem noturna de uma cidade possui muitas facetas e, sem dúvida, estas exigem um grande fôlego para entendê-las em suas relações. Aqui se adotou um caminho em busca das mais lentas mudanças no tempo, associado aos planos, projetos e programas do poder público. Notou-se que, em primeiro lugar, mudanças na organização políticaadministrativa produzem resultados concretos na paisagem, como pode ser visto em relação aos Planos Diretores, projetos urbanos e programas setoriais.

As mudanças urbanas provocam, ao mesmo tempo, transformações no cotidiano, mudando a fisionomia dos lugares, as formas de acessibilidade, os significados e até mesmo o modo pelo qual interpretamos tais lugares. As mudanças ocasionadas pelas decisões dos agentes públicos transformaram também a própria noite, reorganizada, primeiramente, dentro de um zoneamento global do município e, posteriormente, em um eixo estratégico de atuação. A mudança de um discurso de contenção do crescimento que via a luz artificial 
como mecanismo de infraestrutura e bem-estar social para um modelo de gestão eficiente e de valorização estética da paisagem é outro sintoma do processo.

Todas estas mudanças estão lentamente ocorrendo no município e estão neste exato momento se desenrolando. Elas se desenvolvem em um cenário bastante dinâmico do ponto de vista social, pois, articulado com muitos agentes e debatido em meio às diferentes demandas sociais. A linearidade aparente do processo revela mudanças na forma de ver, representar, projetar e agir a/na paisagem noturna. O percurso feito até aqui permite observar o papel crescente da noite nos planos para o município, mas também revela o caráter profundamente pragmático destes planos e projetos. Os efeitos para população são desdobramentos que implicam em observações dos ritmos cíclicos que se intercalam a esse movimento mais lento e contínuo de transformação da paisagem noturna carioca. 


\section{Referências bibliográficas}

BENNETT, J. Vibrant Matter: a political ecology of things. Durham and London: Duke University Press, 2010.

BILLE, M.; e SORENSEN, T. An Anthropology of Luminosity. Journal of Material Culture, v. 12, n. 3, 2007, p. 263-284.

BOGARD, P. Let There Be Night: testimony on behalf of the dark. Nevada: University of Nevada Press, 2008.

BRASIL. Constituição (1988). Constituição da República Federativa do Brasil. Brasília: Senado, 1988.

BRASIL. Lei $\mathrm{n}^{\circ} 10257$ de 10 de Julho de 2001. Regulamenta os artigos 182 e 183 da Constituição Federal, estabelece diretrizes gerais da política urbana e dá outras providências. Diário Oficial da União, 11 de Julho de 2001.

DUNLOP, C. J. Subsídios para a História do Rio de Janeiro. Rio de Janeiro: Imperial Novo Milênio, 2008.

FELDMAN, S. Avanços e limites na historiografia da legislação urbanística no Brasil. Revista Brasileira de Estudos Urbanos e Regionais, n. 4, 2011, p. 33-47.

GÓIS, M.P.F. Paisagens Noturnas Cariocas: formas e práticas da noite na cidade do Rio de Janeiro. 2015. Dissertação (Mestrado em Geografia) - Universidade Federal do Rio de Janeiro. Rio de Janeiro: UFRJ, 2015.

GÓIS, M.P.F. Paisagens Luminosas e Cenários Noturnos: formas, práticas e significados da noite na cidade do Rio de Janeiro. Niterói: Eduff, 2017.

GOMES, P. C. C. O Lugar do Olhar. Rio de Janeiro: Bertrand Brasil, 2012.

GWIAZDZINSKI, L. La Nuit, Dernière Frontière de la Ville. La Tour d'Aigues: Éditions de l'Aube, 2005.

KIRSCHBAUM, C. Iluminação Eficiente de cidades: um enfoque globalizador. In: MASCARÓ, L. (org.). A Iluminação do Espaço Urbano. Porto Alegre: Masquatro, 2006.

LERNER, J. Urban Acupuncture. Washington: Island Press, 2014.

MASCARÓ, L. (org.). A Iluminação do Espaço Urbano. Porto Alegre: Masquatro, 2006.

MEINIG, D. W. The Beholding Eye. In: MEINIG, D. W. (org.). The Interpretation of Ordinary Landscape. Oxford: Oxford University Press, 1979.

MELBIN, M. Night as Frontier. New York: Free Press, 1987.

MENDONÇA, L. L. Reflexos da Cidade: a iluminação pública do Rio de Janeiro. Rio de Janeiro: Centro da Memória da Eletricidade no Brasil, 2004.

MIGUEZ, J.C. L'Urbanisme Lumière: uma nova luz para as cidades. Revista Lumière, n.42, outubro 2001, p. 62-71.

NARBONI, Roger. Lighting the Landscape: art design technologies. Boston: Birkhäuser, 2004.

NOVICK, A. Espaços Públicos e Projetos Urbanos: oposições, hegemonias e questões. Arquitextos, São Paulo, ano 05, n. 054.01, Vitruvius, nov., 2004.

PREFEITURA DA CIDADE DO RIO DE JANEIRO. Lei Complementar do Município do Rio de Janeiro $n^{\circ} 16$ de 04 de Junho de 1992. Dispõe sobre a Política Urbana do Município, institui o Plano Diretor decenal da Cidade do Rio de Janeiro e dá outras Providências.

Diário Oficial do Município do Rio de Janeiro, 09 de Junho 1992, 1 - 36. 
PREFEITURA DA CIDADE DO RIO DE JANEIRO. Lei Complementar do Município do Rio de Janeiro $n^{\circ} 111$ de $1^{\circ}$ de Fevereiro de 2011. Dispõe sobre a Política Urbana e Ambiental do Município, institui o Plano Diretor de Desenvolvimento Urbano Sustentável do Município do Rio de Janeiro e dá outras providências. Diário Oficial do Município do Rio de Janeiro, $\mathrm{n}^{\circ}$ 21, 12 de Abril 2011, 3 - 38.

PREFEITURA DA CIDADE DO RIO DE JANEIRO. Plano Diretor de Iluminação Pública da Cidade do Rio de Janeiro. Rio de Janeiro: IplanRio, 1993.

PROGRAMA NACIONAL DE CONSERVAÇÃO DE ENERGIA ELÉTRICA. Procel Reluz: manual de instruções. Rio de Janeiro: Eletrobrás, 2005.

SANTEN, C. Light Zone City: Light planning in the Urban Context. Zurich: BirkhäuserPublishers for Architecture, 2006.

SCHIVELBUSCH, W. The Policing of Street Lighting. Yale French Studies, n. 73, 1987, p. 61-74. 